\title{
Respiratory home care: take the pulmonary specialist out of the hospital!
}

\author{
G. Garuti, M. Lusuardi
}

Monaldi Arch Chest Dis 2009; 71: 3, 93-95.

Respiratory Rehabilitation, S. Sebastiano Hospital, AUSL Reggio Emilia, Correggio, Italy.

The last three decades have witnessed significant modifications in long-term management of chronic respiratory disorders, in parallel with variations of epidemiological trends and introduction and development of new treatment options to be delivered not only in the traditional health care settings, such as hospitals or out-patient facilities, but also directly at home. A paradigmatic example is represented by a frequent condition of rapidly increasing prevalence, such as COPD (chronic obstructive pulmonary disease); strong evidence has been acquired about the possibility of improving the survival rate and quality of life with timely diagnosis and appropriate treatments (e.g. smoking cessation, inhaled drugs, long-term oxygen therapy, rehabilitation) [1]. This means that more and more patients reach the last phases of the natural history of the disease later in life, when it becomes more difficult in relation to familial or socio-economic problems and major physical disability occur as a result of respiratory failure and co-morbidities. At this point in time, apart from hopefully limited situations where long-term institutional care is needed, the management of such a complex patient may require quite an intense level of home care provision in case of oxygen therapy and mechanical ventilation. According to the American Thoracic Society home care is defined in general as the provision of services and equipment in place of residence of individuals and families who have needs resulting from acute illness, longterm health conditions, permanent disability, or terminal illness [2]. General goals of respiratory home care are to increase survival, reduce morbidity, improve quality of life and function, educate to self-management and positive health behaviours, and support independence. In the case of children with severe respiratory disorders major goals are also to promote optimal growth and development [2].

Apart from COPD, many other conditions of chronic respiratory failure of pulmonary or extrapulmonary origin can be assisted with the advantage of home care, with particular regard to patients dependent on mechanical ventilation (including children), such as subjects affected by progressive neuromuscular disorders.

A national survey [3] and the more recent Eurovent study carried out in 16 European countries with the involvement of 329 Centres and 21526 patients, reported a prevalence of patients on home mechanical ventilation (HMV) of $6.6 / 100,000$ in Europe and $3.9 / 100,000$ in Italy [4]. These figures probably underestimate the real prevalence of HMV, because in several countries, including Italy, a national register of patients on HMV had not yet been constructed at the time of the survey.

Adequate management of patients with severe chronic respiratory failure in the different phases of the disease requires a network integrating different levels of treatment and care including acute-care hospitals, weaning centres, long-term health care centres, pulmonary rehabilitation facilities and respiratory care programmes within home care services $[5,6]$. The care of ventilator-dependent patients in particular requires a multidisciplinary approach, gathering the expertise of many specialists from areas such as pulmonary medicine, respiratory and physical therapy, psychology, speech and swallowing evaluation; nurses must be skilled in the management of airways problems and ventilator care needs.

The need to organise respiratory home care services dates back to the beginning of the 1980s with the development of long-term oxygen therapy [6]. At follow up it became clear that many clinical and technical problems occurred at home and that there had not been foreseen during hospitalisation. In particular, many patients manifested a progressive reduction in time of compliance to the prescribed treatment, nullifying the efficacy of longterm oxygen therapy [6]. These problems have been further amplified by the introduction of HMV [7, 8]. The rapid progression of problems concerning the organisation and the clinical aspects in respiratory home care prompted the major scientific associations of pulmonary Medicine in North America and Europe (including Italy) to promote guidelines on long-term home mechanical ventilation, with a particular emphasis on patients' and care-givers' education about management of HMV outside the respiratory intensive care unit [9, 10]. A few Italian regions have also adopted local guidelines on respiratory home care $[11,12]$. In the near future a strong demand can be foreseen to implement programmes for patients who may require occasional or regular respiratory care at home, integrating hospital, primary care and companies providing technical products and services. Recen-tly, the American Thoracic Society 
underlined that home care must be centred on the specific needs of the patient and on patients' and relatives' satisfaction [2]. This implies that one major focus in home care is quality of life, including terminal patients.

Respiratory home care includes several types of intervention that may be provided regularly, intermittently or for a limited interval of time as needed. In general, equipment delivery and maintenance is demanded to technical services, while personal care is in charge of primary care nurses, either public or private, with possible intervention of other professionals as needed (e.g. respiratory therapist, speech therapist, psychologist, dietician, etc.).

There are large differences in the organisation of respiratory home care from area to area even in the same country, and operative standards are extremely heterogeneous in all the different phases, from early hospital discharge to long-term follow up and from basic nurse intervention to specialistic involvement and tele-medicine. In Europe there are 3 general models: 1. public local health authorities organise and manage home care on their own; 2 . profit or no profit private companies organise and manage home care in formal agreement with public local health authorities, that, at least in Italy, provide also full economical coverage; 3 . a mixing of the first 2 options, as public-private enterprise. In the USA respiratory home care is generally provided by private health agencies certified by a federal organization (Medicare) and professionals are also certified according to a federal regulation.

Home care can decrease hospital costs by reducing the length of stay during an acute event, allowing early supported discharge or preventing further hospitalisations. In addition, from an individual point of view it may improve quality of life of respiratory patients $[2,13,14]$. On the other hand the heavy burden often imposed on families and care-givers must not be overlooked.

Respiratory home care requires specific competence by health personnel, mainly specialised nurses acting as case-manager and programme manager, in agreement and co-operation with primary care physicians. Pulmonologists have developed in recent years specific discharging plans from hospital to home, but at follow up the role of the respiratory specialist is less defined. Medical problems are mainly under the control of the primary care physician, but for chronically critical patients with advanced or even end-stage chronic respiratory failure a very complex clinical picture would often require specialistic consultation.

The paper in this issue from Barbano et al. [15] focuses on the intervention of the pulmonary specialist directly at home of bedridden patients with severe chronic respiratory failure predominantly caused by COPD or amiotrophic lateral sclerosis, evaluating effectiveness and costs. The study demonstrated how the specialist at home may consistently improve patients' and caregivers' satisfaction with costs savings, mainly for caregivers. Some manoeuvres requiring particular experience, such as the periodical change of the tracheostomy tube, generally performed in the hospital, were carried out directly at home by an expert pulmonary specialist with a limited number of complications. Our personal experience in the province of Reggio Emilia, although mainly limited to neuromuscular patients, is very similar to that reported by Barbano et al. The regular home visits of a pulmonary specialist expert in the management of tracheostomy and mechanical ventilation in cooperation with the home nurses, and the application of tele-monitoring in selected cases, has met a great level of satisfaction from patients and families, reducing at the same time the number of hospital admissions. Despite several limitations in the design of the study as acknowledged by Authors, data is very stimulating as a contribution to better define organisation models of respiratory home care, in particular regarding the role of the pulmonary specialist, since studies in literature are mainly focused on nurses and physiotherapists.

Independently from the place where it may be provided, "home care" can be considered in general as an innovative cultural model in contrast to the traditional medical model. The focus on health activities and decisions moves from health professionals to patient/family, who assume direct responsibility for goal setting, decision-making, (self)management, and feed-back for evaluation and improvement with the expert support and co-operation not only from physicians but also from other health professionals, equipment companies, patients' associations, etc. [16]. On the contrary, the translation of the home care concept into practice depends on so many hard variables (political system, economic resources, social structure, cultural and religious values, graduate and post-graduate education of health professionals, organization of the local health service, etc.). This means that a comparison among the different models in the different health systems becomes extremely difficult. In turn, it is important that researchers try to define common standards and outcome measures but inevitably, each model will have to be investigated rigorously taking into account the peculiarities at a local level.

\section{References}

1. Global Strategy for the Diagnosis, Management and Prevention of COPD, Global Initiative for Chronic Obstructive Lung Disease (GOLD) 2006. Available from: http: //www.goldcopd.org.

2. ATS Documents. Statement on Home Care for Patients with Respiratory Disorders. Am J Respir Crit Care Med 2005; 171: 1443-1464.

3. Gasperini M, Clini E, Zaccaria S. Mechanical ventilation in chronic respiratory insufficiency: report on an Italian nationwide survey. Monaldi Arch Chest Dis 1998; 53: 394-399.

4. Lioyd-Owen SJ, Donaldson GC, Ambrosino N, Escarrabil J, Farre R, Fauroux B, et al. Patterns of home mechanical ventilation use in Europe: result from the Eurovent survey. Eur Respir J 2005; 25: 1025-1031.

5. Ferrero E, Escarrabil J, Prats E, Maderad M, Manresa F. Impact of a hospital-based home-care program on the management of COPD patients receiving long-term oxygen therapy. Chest 2001; 119: 264-369.

6. Pepin JL, Barjhoux CE, Deschaux C, Brambilla C, on 
behalf of the ANTADIR Working Group on Oxygen Therapy. Long-term Oxygen Therapy at Home. Compliance with medical prescription and effective use of therapy. Chest 1996; 109: 1144-1150.

7. Plummer AL, O’Donohue WJ, Petty TL. Consensus Conference on Problems in Home Mechanical Ventilation. Am Rev Respir Dis 1989; 140: 555-560.

8. DeWitt PK, Jansen MT, Ward SLD, Keens TG. Obstacles to discharge of ventilator -assisted children from the hospital to home. Chest 1993; 103: 1560-1565.

9. American College of Chest Physician. Mechanical ventilation beyond the intensive care unit: report of a consensus conference of the American College of Chest Physicians. Chest 1998; 113: 289s-344s.

10. MacIntyre NR, Epstein SK, Carson S, Scheinhorn D, Christopher K, Muldoon S. Management of Patients Requiring Prolonged Mechanical Ventilation - Report of a NAMDRC Consensus Conference. Chest 2005; 128: 3937-3954.

11. Regione Lombardia. Definizione delle linee guida per la
Ventiloterapia meccanica domiciliare. Decreto n. 5358 (12/03/01) della Direzione Generale Sanità.

12. Regione Veneto. Linee guida regionali sul trattamento a domicilio con nCPAP nella sindrome da apnee ostruttive nel sonno. D.G.R n. 4285 del 29/12/04.

13. Sala E, Alegre L, Carrera M, Ibars M, et al. Supported discharge shortens hospital stay in patients hospitalized because of an exacerbtaion of COPD. Eur Respir J 2001; 17: $1138-1142$.

14. Hernandez C, Casas A, Escarrabill J, et al. Home hospitalisation of exacerbated chronic obstructive pulmonary disease patients. Eur Respir J 2003; 21: 58-67.

15. Barbano L, Bertella E, Vitacca M. Episodic medical home interventions in severe bedridden chronic respiratory failure patients: a 4 year retrospective study. Monaldi Arch Chest Dis 2009; 71: 113-118.

16. Goldberg AI. Ethical/regulatory issues concerning longterm mechanical ventilation. In: Donner CF, Ambrosino N, Goldstein RS, eds. Pulmonary rehabilitation. Hodder Arnold, London 2005; pp 377-385.

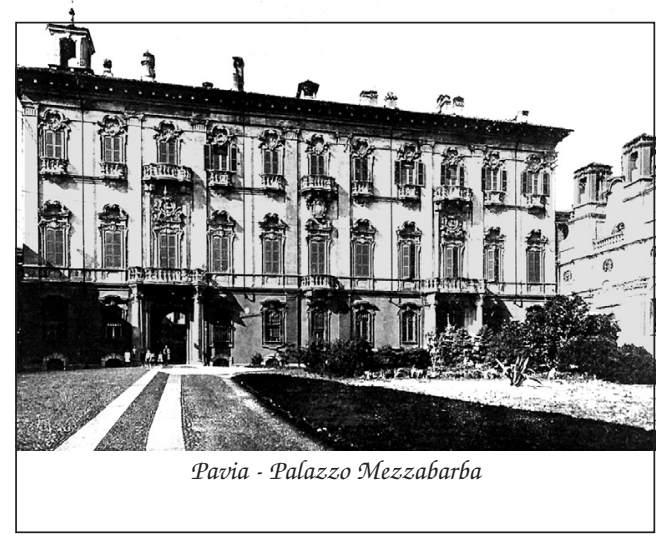

